\title{
CAPS judiciário: Opção necessária para uma justiça saudável
}

\author{
CAPS judiciary: Necessary option for a bealthy justice
}

\author{
Nelson Rocha de Oliveira ${ }^{[\mathrm{a}]}$, Raquel Maria Batista Arraes ${ }^{[\mathrm{b}]}$
}

[a] Doutor em Ciências do Comportamento, professor de Saúde Mental da Faculdades Integradas da União Educacional do Planalto Central (Faciplac), Gama, DF - Brasil, e-mail: espirito@unb.br

[b] Graduada em Enfermagem pelas Faculdades Integradas da União Educacional do Planalto Central (Faciplac), Gama, DF - Brasil, e-mail: nursearraes@gmail.com

\section{Resumo}

O presente artigo apresenta as bases teóricas para a extensão do serviço substitutivo de atenção em saúde mental para o "louco infrator". Propõe-se a criação de um novo modelo de Centro de Atenção Psicossocial que atenda aos usuários internos em hospitais de custódia, manicômios judiciários ou alas de tratamento psiquiátrico de presídios. Com um enfoque argumentativo, são dadas as diretrizes e os parâmetros de implementação do ora denominado Centro de Atenção Psicossocial Judiciário (CAPSj). São apresentadas as razões para sua criação, o funcionamento e a estrutura; são refutadas as críticas à ideia e discorre-se sobre o impacto positivo ao sistema prisional e à sociedade.

Palavras-chave: Hospital de custódia. Centro de Atenção Psicossocial. Louco infrator.

\begin{abstract}
The article presents the theoretical bases for the extension of the substitutive service of attention in mental health for the offenders with mental illness. It proposes new model for a Center of Psychosocial Attention Center that would assist internal users from custody hospitals, forensic psychiatric hospitals or psychiatric ward in prisons. The guidelines and parameters for implementation the center denominated Judiciary Center of Psychosocial Attention (CAPSj), are presented. Also, the rational for this proposal, the functioning and structure are presented; finally, the paper discusses the criticism to this proposal and the contributions for the prisional system and the society.
\end{abstract}

Keywords: Custodian hospital. Psychosocial Attention Center. Mental illness offenders. 


\section{Introduçáo}

Desde o início das civilizações o transtorno mental desperta preocupação em todas as esferas que compõem a sociedade, e as percepções acerca dele sofreram mudanças e ressignificações ao longo da história (Castro, 2009, p. 26). Tal transtorno provoca desconforto e o indivíduo deixa de agir pelos padrões esperados de funcionalidade, mesmo que temporariamente, pois sua doença o impossibilita de desenvolver suas atividades de forma adaptativa mergulhando-o em uma desrealidade artificiosa, inteiramente estranha e com a capacidade de julgamento alterada, tornando difícil o ajustamento comportamental às expectativas do meio social onde está inserido.

$\mathrm{Na}$ Idade Média relacionava-se o transtorno mental a aspectos místico-religiosos, ligando-o aos deuses e demônios e sendo por eles governado. Assim, os doentes mentais eram alvo de preconceitos, isolamento social e de um tratamento desumano, posto que, vistos como pessoas possuídas pelo demônio, eram passíveis de influenciar negativamente as comunidades (Castro, 2009, p. 26; Nunes, Bueno \& Nardi, 2001).

Dessa forma, as pessoas que sofriam com transtorno mental ficavam aglomeradas nos antigos leprosários, largadas pelas ruas, deixadas à própria sorte, vagando pelas cidades. Podiam ainda ser confiadas aos marinheiros das conhecidas "naus dos loucos" para serem enviadas às cidades santas com a finalidade de alcançar a cura divina ou ainda eram recolhidas pelo Estado e depositadas nas prisões por cometerem delitos, ficando entre os presos comuns (Foucault, 2007, p. 9-12).

Apenas no século XVIII, e graças a Philippe Pinel, foram retiradas as correntes dos loucos que viviam trancados em celas nos asilos e deu-se início a ações que visavam a melhorar a conduta para com eles.

No entanto, percebeu-se que o aprisionamento de pessoas com transtornos mentais em manicômios poderia ser fator de agravamento da patologia e, possivelmente, razão do surgimento de outras. O efeito disso foi o surgimento, ao final da década de 70 de uma corrente de pensamento que visava à modificação das políticas de saúde mental e que foi denominada de movimento da reforma psiquiátrica (Brasil, 2005, p. 6).

Como resultado, foram criados serviços que tinham como objetivo substituir o modelo asilar e segregador no qual se transformou a instituição psiquiátrica, ora destinada a acolher e tratar, e que marcou todo o século passado. Os novos serviços surgiram apoiados pela diretriz do acolhimento, promoção da autonomia e suporte ao núcleo familiar. A equipe multidisciplinar passa a ser de fundamental importância, dada a necessidade de uma abordagem centrada na diversidade e na riqueza que a psique humana exige. Esse novo enfoque mudou dramaticamente a forma de ver o louco na sociedade e pôde lhe abrir as portas de um mundo mais humano e menos ameaçador.

Embora a sociedade tenha avançado no tratamento ao portador de transtorno mental comum, ela ainda tem que lidar com o problema daqueles que cometeram delitos e que possuem um diagnóstico psiquiátrico. Essa permanece uma questão em aberto e merecedora de atenção e análise e é a proposta do presente artigo.

Atualmente, os portadores de transtorno mental que cometem delitos são mantidos sob a custódia do Estado com o título de "loucos infratores", por meio de uma medida de segurança que determina a pena mínima, e não a máxima. Essa pena varia de um a três anos e se estende até que seja concedido um atestado de cessação de periculosidade, assinalando que inexiste a probabilidade de reincidir no delito (Castro, 2009, p. 61; Peres \& Nery Filho, 2002, p. 2009; Oliveira, 2009, p. 113-114). Esse atestado de cessação de periculosidade deve ser emitido por dois psiquiatras forenses indicados pela autoridade judicial competente, que pode indeferir o parecer técnico caso entenda necessário (Castro, 2009, p. 62). No entanto, essa pena pode prosseguir indefinidamente, fazendo com que o tempo de estada em manicômios judiciários não seja contado da mesma forma que nas situações em que uma pena máxima foi determinada.

Apesar da diretriz da medida de segurança ter o intuito de reeducar e tratar, o que diminuiria a probabilidade da reincidência de delitos, a estrutura em que se recebe o usuário com transtorno mental é precária, o que leva a crer que o processo de melhora e ressocialização ainda não atende aos objetivos primeiros.

Esses pacientes que ficam sob a custódia do Estado são definidos pelo Código Penal Brasileiro como inimputáveis ou semi-imputáveis (Decreto Lei n. 2.848 de 7 de dezembro de 1940, art. 26; Nucci, 2006). Sendo inimputáveis definidos como "incapazes de entender o caráter ilícito da 
ação delituosa” (Dantas \& Chaves, 2007) e semi-imputáveis definidos como sujeitos que possuem sua culpabilidade diminuída por estarem em um estado fronteiriço entre a completa sanidade mental e o estado patológico e, portanto, não podem ser mantidos juntos com outros presos, ficando em manicômios judiciários (Peres \& Nery Filho, 2002, p. 339; Oliveira, 2006, p. 47-48; Prado, 2006, p. 422-423). Contudo, essas instituições não são geridas pelo SUS, mas, sim, por órgãos da justiça. Não estando, dessa forma, sujeitas às normas do Sistema Único de Saúde não são fiscalizados pelo PNASH/Psiquiatria, o que dificulta o planejamento estratégico para essa classe de pacientes.

O manicômio judiciário foi instituído no Brasil na segunda década do século XX, sua criação se deu a partir de amplos debates no campo jurídico-penal sobre a loucura criminosa, nos quais estavam também incluídos os presos que enlouqueciam nas prisões. Essa instituição posteriormente passou a ser denominada como Hospital de Custódia e Tratamento Psiquiátrico (HCTP), conforme previsão do Código Penal Brasileiro nos seus artigos 96 e 97 e na Lei de Execução Penal no artigo 99 (Dantas \& Chaves, 2007; Correia, Lima \& Alves, 2007). O modelo de tratamento oferecido nessas instituições psiquiátricas tem sido marcado por violência e pelo grande número de óbitos em suas unidades (Brasil, 2005, p. 7). Esses HCTPs são ambientes ambíguos desde a sua formação, pois são ao mesmo tempo um espaço prisional e asilar, penitenciário e hospitalar, para onde se enviam aqueles com quem a sociedade não sabe ou não deseja lidar.

Tem-se apontado que a medida de segurança culmina por tornar perene a estada do reeducando em hospitais de custódia, tornando, ainda, remota a possibilidade de retomada dos vínculos sociais e afetivos (Araújo, 2006, p. 234-235; Lopes, 2002; Giovani, 2005; Valamiel, 1994).

Por serem instituições da justiça, e não estarem ligados a órgãos de saúde regidos pelo SUS, os hospitais de custódia e tratamento psiquiátrico não acompanharam a evolução do pensamento derivado da reforma psiquiátrica. Isso abre brecha para a manutenção de práticas já abolidas em instituições públicas, para a violência, abusos e óbitos, visto que a própria organização dessas instituições se fundamenta na exclusão e no isolamento (Wunderlich, 2006; Ramos \& Geremias, 2009). Se de um lado o vínculo a serviços substitutivos é restaurador de equilíbrio pessoal, familiar e social, o HCTP permanece estacionário em um tempo anterior à reforma. $\mathrm{E}$, ainda, os seus usuários não têm visibilidade social e, por isso, sua condição causa pouco impacto sobre a opinião pública ou nos trabalhadores da saúde mental. Ele é uma das últimas fronteiras para instauração da reforma psiquiátrica no Brasil, permanecendo como um obstáculo desafiador a ser vencido. Seus usuários não incomodam (como deveriam) porque não são vistos, e o confinamento, juntamente com o transtorno mental, criam uma dupla condição de exclusão e um duplo motivo para o preconceito.

Algumas iniciativas nobres de desinstitucionalização rápida estão em curso. Pode-se citar o Programa de Atenção Integral ao Louco Infrator (PAI-LI) de Goiânia, o Programa de Atenção Integral ao Paciente Jurídico (PAI-PJ) de Belo Horizonte, e ainda o programa não oficializado, que existe desde 2002 em Brasília, que visa à ressocialização dos pacientes que estão há mais de cinco anos reclusos em Ala de Tratamento Psiquiátrico, inserindo-os no CAPS do Instituto de Saúde Mental (ISM) durante o dia, com retorno ao presídio no fim da tarde durante os dias úteis; o impacto benéfico seria maior havendo uma sistematização da assistência por um órgão da saúde, que derivaria em ações de longo prazo e resultados de curto prazo, aumentando o número de beneficiários da política de inclusão do SUS (Castro, 2009, p. 80).

Esses indivíduos estão, apesar de próximos do nosso convívio, condenados à obscuridade social, familiar e individual, por se encontrarem encobertos pela escassez de informações passadas à sociedade e pela incapacidade do sistema penal em lhes estender todos os recursos de tratamento disponíveis a outros doentes.

Partindo do princípio de que todo cidadão tem direito ao melhor serviço de saúde disponível, a exclusão dos inimputáveis e semi-imputáveis da Reforma Psiquiátrica éincongruente com um Sistema Único de Saúde que pretende oferecer saúde a todos. Com vistas a corrigir as distorções da dupla exclusão, este artigo sugere a criação de um Centro de Atenção Psicossocial especializado nos transtornos mentais da população carcerária, que passamos a denominar de CAPS Judiciário ou CAPSj. Ele nasceria com a função de estender as mãos do SUS aos presidiários portadores de transtornos mentais de forma a buscar sua reintegração à sociedade, da mesma forma que os CAPS atuais o fazem com os clientes usuais. 


\section{Metodologia}

Realizou-se um trabalho teórico (argumentativo), cuja função foi justificar e delinear a implementação do Centro de Atenção Psicossocial Judiciário (CAPSj), tendo em vista a relevância dessa instituição para a sociedade e seus respectivos usuários.

\section{Por que um novo modelo de CAPS?}

Os Centros de Atenção Psicossocial têm se mostrado eficientes na tarefa para a qual foram designados. Eles proporcionam um espaço de intervenção gerador de autonomia aos portadores de sofrimento psíquico por serem calcados na conjugação de saberes da equipe multiprofissional e pela visão humanizadora trazida em sua configuração original, conforme o estabelecido na Lei n. 10.216 de 6 de abril de 2001, no seu art. $2^{\circ}$ parágrafo único e art. $4^{\circ} \int 1^{\circ}$ (Brasil, 2004, p. 17-19). Mas, apesar de tantos avanços oferecidos, os internos em manicômios judiciários ainda não podem ser beneficiados integralmente por esse modelo de atenção em saúde, dada a particularidade de suas situações e, por isso, continuam sendo vitimizados pela exclusão e pelo preconceito.

O modelo de atenção em saúde mental no Brasil tem tido maior sucesso que o modelo manicomial quanto ao atendimento à parcela da população adoecida mentalmente. No mínimo, as ações atuais resgataram a cidadania e devolveram a esperança para milhares de pessoas. A exceção no sistema é a população carcerária que necessita de tratamento psiquiátrico, pois ainda não foi conseguido se articular para inserir efetivamente seus doentes nos serviços substitutivos, embora o tratamento integral à saúde tenha sido previsto pela Portaria Interministerial n. 628, de 2 de abril de 2002 (Brasil, 2004, p. 67-92).

Para uma eficiente intervenção ao problema apresentado, é pungente a adoção de um novo passo na direção da assistência integral. Isso se daria pela criação de uma unidade de referência para atenção básica.

Portanto, a criação do CAPSj ocupará a lacuna da promoção da melhor assistência em saúde para esse grupo de pacientes, pelo simples fato de dinamizar o atendimento por meio de atividades reabilitadoras, terapêuticas e educativas, servindo ainda para encaminhamento aos CAPS de saúde mental ou de álcool e drogas, redesenhando a porta de saída do manicômio e da doença.

É preciso ressaltar que qualquer avaliação feita pela equipe multiprofissional, que conhece as nuances do comportamento de cada interno, se recobre de grande fidedignidade. Relatórios gerados por equipe especializada em psiquiatria e psicologia forense podem ser mais eficazes em "evitar que indivíduos que não estão preparados para a convivência social sejam equivocadamente liberados (tenham cessação da periculosidade)" (Santos, 2007, p. 12). Esse procedimento estaria de acordo com a prática de avaliação dos usuários, hoje vigente no Brasil, em que a equipe multiprofissional gera conhecimentos sobre o indivíduo, sua vida social e familiar, seus sintomas e a evolução do quadro clínico.

A proposta do CAPSj se calca na reformulação do atendimento psiquiátrico para os internos em penitenciárias e hospitais de custódia, juntamente com o suporte às famílias, muitas vezes também adoecidas. É a ampliação da rede de assistência em saúde mental aos encarcerados, auxiliando o próprio sistema penitenciário a se reerguer de suas imensas dificuldades pela promoção e prevenção da saúde mental. Ele surgiria, portanto, como uma promessa para a otimização da recuperação dos mais diversos indivíduos com adoecimento psíquico.

O que se propõe são a extensão do atendimento e a sistematização de ações que já se mostraram eficazes no modelo implantado pela reforma psiquiátrica. Essa instituição nasceria com capacidade operacional de assistir às particularidades inerentes a essa população e lhes proporcionar os cuidados especiais de que necessitam. Isso resultaria no alívio dos sintomas e do sofrimento, auxiliando, como consequência, na redução do tempo de cárcere. Outra função da instituição é aumentar a quantidade de conhecimento em psiquiatria e psicologia forense pelo aumento do número de profissionais envolvidos na compreensão dos agravos e pela abertura do ambiente a pesquisas científicas.

A criação desse espaço incentivaria a inclusão desse tema na formação dos profissionais, tanto da saúde como dos operadores jurídicos, dando uma perspectiva do direito à saúde e vice-versa (Correia, Lima \& Alves, 2007).

A implantação do CAPSj diminuiria, ainda, o impacto da desarticulação na atenção aos encarcerados portadores de sofrimento psíquico, minimizado os efeitos negativos da ausência de rede específica 
de assistência. Todos esses fatores contribuiriam para menores taxas de reincidências em delitos e diminuição da frequência das crises.

\section{Como o CAPSj se estruturaria?}

Mesmo a população que tem autonomia para buscar o serviço público de saúde encontra dificuldades em conseguir atendimento, e esse quadro é agravado relativamente quando a pessoa que necessita de tratamento não é capaz de responder por suas ações e seu bem-estar físico e mental. Desse modo, os CAPS, atendendo ao disposto pela Portaria GM 336 de 19 de fevereiro de 2002, devem estar localizados em uma área de fácil acesso à população e contar com um ambiente que favoreça o acolhimento, a hospitalidade, a integralidade e a equidade da assistência (Brasil, 2004, p. 125-136).

Por configurarem-se como serviços comunitários ambulatoriais e regionalizados, nos quais os pacientes deverão receber consultas médicas, atendimentos terapêuticos individuais e/ou grupais, participando de ateliês abertos e atividades lúdicas e recreativas promovidas pelos profissionais do serviço, de acordo com um projeto terapêutico individualizado. Devem igualmente ser voltados para o tratamento e reabilitação psicossocial, com iniciativas extensivas aos familiares e às questões de ordem social presentes no cotidiano dos usuários, os CAPS representam uma oportunidade real de reinserção social dos seus usuários (Onocko Campos \& Furtado, 2006).

Essa instituição seguiria as normas já estabelecidas pelo Ministério da Saúde e se classificaria como um CAPS para atendimento de adultos, assistindo detentos com transtornos mentais severos e persistentes. Seguindo os parâmetros da legislação vigente, seriam CAPS adequados ao tamanho da população, podendo ser instalados em todo o território nacional, para atender à demanda carcerária com transtornos mentais e proporcionar-lhes o atendimento necessário para sua recuperação e reinserção social. É uma proposta de inclusão para pessoas que estão sob a custódia do Estado e sofrem pela precariedade de atendimento pelo SUS.

Sendo assim, a proposta do CAPSj está inserida nesse contexto de acessibilidade da assistência, acolhimento ao paciente portador de transtorno mental, atendimento multiprofissional e dinamismo terapêutico, por meio de uma perspectiva psicossocial que entende como relevantes os temas da vida diária que comumente não são levados em consideração quando se aborda a doença mental apenas como uma sintomatologia a ser tratada, ou seja, lazer, moradia, trabalho, aspirações individuais, relacionamentos afetivos, etc. Tudo isso realizado por meio de uma terapêutica voltada para a diversidade das problemáticas de quem sempre esteve à margem do atendimento prestado pelo sistema público de saúde.

Essa abordagem visa ao aperfeiçoamento e à humanização do atendimento psiquiátrico e ao estabelecimento de medidas que viabilizem o acesso aos serviços de saúde para os presidiários em adoecimento psíquico, pois são alvo de dupla discriminação e preconceito e sofrem, ainda, com a falta de profissionais especializados em psicologia e psiquiatria forense nas unidades de saúde de que dispõem, excluindo-os do necessário atendimento à saúde mental, gerando, portanto, uma segregação maior que a causada pela sua patologia (Brasil, 2005).

Algumas alternativas foram desenvolvidas em iniciativa conjunta dos Ministérios da Justiça e Saúde, tendo em vista amenizar o impacto causado pelo recolhimento em estabelecimentos prisionais com a proposta de incluir os presos nas ações de promoção e atenção à saúde preconizada pelo SUS (Portaria Interministerial n. 628, de 2 de abril de 2002). Dessa forma criou-se o Plano Nacional de Saúde no Sistema Penitenciário, que objetiva oferecer um suporte assistencial à saúde, condições salubres de confinamento e acesso a atividades físicas, bem como o tratamento de doenças infecto-contagiosas, acesso a medidas de proteção especifica (vacinação) e assistência à saúde bucal e psicológica (Brasil, 2004, p. 67-92, Brasil, 2005).

Mas esse suporte ainda não é suficiente para atender à demanda de indivíduos que necessitam de apoio em saúde mental especializado, visto que, apesar de ter por finalidade a implantação de ações que garantam acesso à saúde, como previsto na Lei n. 7.210 de 11 de julho de 1984, no art. 11, $\int 2^{\circ}$ e art. 14, $\int 2^{\circ}$ e $3^{\circ}$ (Brasil, 1984), a todas as pessoas que se encontram segregadas do convívio social em penitenciárias, colônias penais agrícolas ou agroindustriais e hospitais de custódia e tratamento psiquiátrico, esse serviço não dispõe da estrutura e fiscalização necessárias para garantir que os desafios propostos pela reforma sejam todos atingidos.

A estruturação desse modelo de assistência, portanto, deve ser percebida na realização da mediação entre o ato jurídico e a abordagem clínica, criando-se 
o CAPSj a partir de uma dinâmica que assimile tanto o princípio da integralidade quanto o da equidade previstos peloSUS e pelos direitos humanos (Correia, Lima \& Alves, 2007).

O atendimento no CAPSj deve seguir a orientação para um CAPS misto de saúde mental e álcoole drogas, e questões como frequência de sessões, horários de oficinas terapêuticas e ações que visem a promover a inserção social dos usuários, como terapias educativas em trabalho, esporte, cultura e lazer devem ser estruturados e organizados de modo a possibilitar o enfrentamento dos problemas e o desenvolvimento das capacidades individuais além da integração dos indivíduos no trabalho em conjunto e na convivência em sociedade (Lisboa 2002; Brasil, 2004, p. 125-136). As oficinas terapêuticas devem ser desenvolvidas de modo a estimular o desenvolvimento de habilidades físicas e sociais inexistentes ou pouco trabalhadas na pessoa.

Essas oficinas terapêuticas precisam funcionar dentro da própria instituição com a participação de toda a equipe multiprofissional e com os familiares, com o intuito de criar laços de solidariedade entre eles e promover um ambiente de mútua confiança entre profissionais, familiares e pacientes (Peduzzi, 2001).

Caberá a esse serviço o atendimento ambulatorial, oatendimento diurno ou noturno por uma equipe de profissionais qualificados, responsáveis por desenvolver terapêuticas individuais e em grupos, buscando a adaptação social do indivíduo e sua melhor condição de vida. Deverá organizar suas atividades e equipe para receber toda ademanda do seu território. Essa instituição pode servir como referência para pronto atendimento aos internos com transtornos mentais, desde que seja planejada para tal. Deverá, ainda, oferecer atividades dinâmicas e fundamentais ao tratamento, tendo uma importância primordial no processo saúde-doença e também na recuperação de pessoas.

O CAPS judiciário, como um reflexo da sua equipe, também necessita trabalhar em conjunto, articulando-se com os demais modelos assistenciais substitutivos e projetos governamentais que têm por objetivo a reinserção social. Eles devem integrar os CAPS de saúde mental, os CAPS de álcool e drogas, as equipes de saúde da família e agentes comunitários de saúde, visando à promoção da vida, articulando suas ações em outras redes, como escolas, universidades, locais de trabalho, instituições sociais e assim por diante (Brasil, 2004, p. 125-136).

Nesse contexto, o compromisso do serviço nesse novo modelo de CAPS é de retirar a loucura do enclausuramento e do isolamento em que vive há tantos anos, direcionando suas ações para o desenvolvimento de projetos terapêuticos e comunitários inspirados na capacitação como preparo para o retorno à sociedade, acompanhando os usuários em seu ambiente domiciliar por meio de um atendimento estruturado com a finalidade de devolver ao convívio social o portador de doença mental infrator, reeducado, tratado e recebendo todo apoio necessário para prevenir a reincidência e diminuir/ controlar novas crises, contribuindo, assim, com a proteção e o bem-estar da sociedade.

\section{Qual a composiçáo da equipe multiprofissional?}

Quando se fala em equipe multiprofissional quer-se falar de um grupo composto por pessoas que adquiriram experiência e conhecimentos direcionados a um tema específico, eque estejam legalmente habilitadas a conduzir processos terapêuticos e emitir opinião sobre questões relevantes de sua área de trabalho. Essa equipe tem por objetivo realizar um atendimento integral de seus pacientes, por organizar-se de forma a compreender diversas áreas que envolvem a vida humana por meio de um olhar ao mesmo tempo especializado e abrangente, a partir da formulação de um projeto assistencial comum.

A equipe multiprofissional de que necessita o modelo de CAPS proposto neste artigo vai além da abordagem estritamente técnica, predominante em toda a assistência em saúde, que se compreende apenas como uma equipe interdisciplinar utilizada como recurso para aumentar a produtividade focada nos resultados. Essa equipe está mais voltada para as relações interpessoais e para os processos psíquicos envolvidos por meio da articulação dos saberes especializados em saúde (Peduzzi, 2001; Milhomem \& Oliveira, 2007).

Essa equipe deve ser composta por psicólogos e psiquiatras forenses, enfermeiros especialistas em saúde mental e outros profissionais de nível superior (Correia, Lima \& Alves, 2007; Brasil, 2009; Abuhab, Santos, Messenberg, Fonseca \& Aranha e Silva, 2005) organizando-se de modo a produzir relatórios conjuntos, tornando mais precisas as avaliações e pareceres, diminuindo a margem de erros e, como consequência, deixando de expor a população geral aos possíveis danos advindos de avaliações 
imprecisas. Técnicos de enfermagem, oficineiros e pessoal de apoio são fundamentais para a condução do trabalho. A equipe prescinde da presença da polícia ou carcereiros, salvo nos casos especiais em que se necessite de escolta para atendimentos, de modo a evitar descaracterização da instituição de saúde.

A equipe multiprofissional deve agir de maneira integrada para oferecer a necessária interdisciplinaridade que envolve um projeto terapêutico estruturado, e individualizado, voltado para o quadro clínico e o perfil psicológico dos pacientes.

Reuniões frequentes são importantes, viabilizando um conhecimento mais amplo da história dos pacientes e uma melhor compreensão e avaliação do caso, além de planejamento da conduta organizacional necessária para que sejam localizados os entraves de modo a otimizar a assistência (Abuhab et al., 2005).

Uma equipe que saiba refletir, aceitar e ter motivação para otimizar a assistência prestada é essencial no processo de melhora do usuário. Para isso, torna-se necessária a organização, a comunicação, o contato efetivo entre seus membros de modo a contribuir para a melhora dos sintomas do indivíduo. A diversidade, portanto, pode auxiliar o ser humano em sua multiplicidade, no seu próprio contexto e nas relações dinâmicas do ambiente onde está inserido (Abuhab et al., 2005).

\section{Quais são as críticas à ideia?}

Algumas críticas têm surgido com respeitoà ideia de criação de um CAPS voltado para a população com transtorno mental dos manicômios judiciários ou encarcerados. É bem possível que tais críticas tenham surgido em função do tema despertar zelo ou cuidado especial em sua abordagem ou, ainda, estranhamento à ideia de mais um serviço substitutivo, já que foge ao que se tem como usual em saúde mental. É possível também que essa população diferenciada cause receios em algumas pessoas, de modo a evitar discussões que levem à abordagem a uma classe de indivíduos que, por si só, desperta medo e precauções.

A primeira crítica é que um CAPS judiciário, por lidar com pessoas que cometeram delitos, e que já vivem à margem da sociedade, terá o efeito de aumentar o preconceito com esses usuários. Ora, ações que visem a corrigir problemas com o atendimento de uma população com requisitos especiais devem ser dirigidas a partir de uma abordagem especial.
Além do mais, a proposta não é segregatória, já que uma função central desse serviço substitutivo será o encaminhamento aos CAPS de saúde mental, de álcool e drogas e residências terapêuticas, permitindo o trânsito de internos para a ressocialização. Se fosse válida a argumentação para esse caso, ela também seria válida para os CAPS de álcool e drogas ou da infância e adolescência. Esses serviços, por sua vez, se mostraram úteis aos fins a que foram destinados e, portanto, permanecem cumprindo seu importante papel.

Outro apontamento que tem surgido é que se deve simplesmente encaminhar os usuários aos serviços substitutivos atuais, não havendo necessidade de criação de mais um tipo de CAPS. Mas é preciso salientar que os serviços substitutivos devem, fundamentalmente, fazer parte da rede de acolhimento desses usuários; no entanto, eles não estão preparados para atender toda a demanda do sistema prisional, no que tange à equipe e estrutura física. A função do CAPSj é tratar e encaminhar, além de orientar outras equipes ao acolhimento. Ele, além do tratamento especializado, fará a ponte entre o hospital de custódia e outros serviços de saúde.

Pode-se pensar também que haveria problemas na segurança do CAPS j, porque, em ele existindo, o serviço seria apenas um hospital de custódia repaginado, com um novo título. A observação é procedente e deve guiar os gestores de modo a evitar o equívoco da sobreposição do modelo. É preciso pensar que um serviço substitutivo não deve cometer os erros da institucionalização falida em superação no Brasil, e toda atenção deve ser dirigida de modo a se manter um nível satisfatório de segurança apenas aos indivíduos que ela inspirem, sem a generalização geradora de erros. Caberáà equipe selecionar individualmente os usuários que deverão participardas atividades do CAPSj e indicar quais abordagens são indicadas em cada caso.

Outro problema relacionado à segurança seria o risco de fuga para os internos que não receberam a cessação da periculosidade, caso seja copiado o modelo de reintegração dos serviços substitutivos. Embora esta seja uma observação pertinente, a prática de atendimento realizada por CAPS em Brasília, DF, a usuários provenientes do sistema prisional, mostra que esse risco é mínimo e que prevalece a relação de cuidado típica de um serviço de saúde.

Novas críticas fundamentadas podem aparecer e terão a função de apontar fragilidades que devem ser corrigidas e alertar os gestores quanto ànecessidade de aperfeiçoar o funcionamento da instituição. 


\section{Qual o impacto da implantaçáo do CAPSj?}

Permanece uma questão incompreensível: o fato das ações em saúde mental do sistema substitutivo terem pouco ou quase nenhum impacto sobre aqueles que estão sob medida de segurança em hospitais de custódia e tratamento psiquiátrico. Muitos permanecem esquecidos à própria sorte $\mathrm{e}$ invisíveis, inclusive, aos trabalhadores da saúde. Essa discriminação acaba por se manifestar impeditiva a um tratamento digno e à reinserção social.

A ideia não defende o fim dos hospitais de custódia, mas oferece um impulso positivo na melhora das condições de funcionamento do sistema prisional como um todo, já que podem ser atingidos também os portadores de transtornos de personalidade.

A medida incentiva que as instituições prisionais liberem pacientes que não tenham necessidade de permanecer hospitalizados. Por outro lado, a redução do número de pacientes internados permitirá que os hospitais de custodia deem uma atenção mais humanizada e diferenciada a esses pacientes.

A proposta atinge, igualmente, o paradoxo criado pela medida de segurança de estabelecer apenas um período mínimo de custódia, por criar uma rota de saída na medida da evolução do quadro, personalizando os casos e protegendo o louco infrator em sua integralidade. E uma forma humanizadora de tratamento, embora tardia, de prevenção de agravos derivados do ambiente hostil onde vivem e do longo período de cárcere.

A criação do CAPSj facilitaria a implantação de programas psicossociais ao sistema prisional brasileiro, de forma a amparar presos de outras categorias e auxiliar a própria justiça na difícil tarefa de reabilitação.

Pensa-se, ainda, que a implantação dessa instituição resultaria em uma sociedade mais segura, inaugurando uma nova fase da assistência em saúde prisional, significando uma ampliação da rede e dando diretividade às ações pertinentes à população carcerária.

\section{Consideraçóes finais}

Este artigo apresenta uma proposta de solução ao sério problema pelo qual passam os infratores portadores de sofrimento psíquico e que estão cumprindo medida de segurança. Sofrem eles dupla discriminação por estarem confinados ao cárcere e por possuírem um transtorno mental. Além disso, as instalações dos hospitais de custódia não oferecem as oportunidades de um serviço substitutivo e acabam por reproduzir o manicômio que se quer banir do País. Isso acaba por influenciar na melhora por impor barreiras ao resgate do convívio social e ao melhor tratamento disponível.

A indefinição do tempo máximo de internação no hospital de custódia pode ser devidamente contornada na medida em que o CAPSj, enquanto instituição criada para prestar serviços adequadamente sistematizados em saúde mental, realize atendimentos sistemáticos individuais e em grupo, realize oficinas terapêuticas e promova ações de reabilitação psicossocial. Tais atividades devem estar integradas à rede de serviços substitutivos de modo a encaminhar os usuários aos CAPS de saúde mental e álcool e drogas.

Em razão dos sérios problemas enfrentados pelo sistema prisional, uma resposta adequada deve ser considerada, e essa resposta já foi dada pelo SUS na medida em que cria serviços que visam a substituir o modelo anacrônico, que provou ser ineficiente e precário. A criação da nova modalidade de CAPS - o CAPS $\mathrm{j}$ - auxiliará a justiça brasileira a abordar com eficiência e prontidão parte de suas limitações com indivíduos infratores. Além disso, oferece as condições para tratamento sistemático de portadores de transtornos de personalidade que ainda não são atendidos rotineiramente.

\section{Referências}

Abuhab, D., Santos, A. B. A. P., Messenberg, C. B., Fonseca, R. M. G. S., \& Aranha e Silva, A. L. (2005). O trabalho em equipe multiprofissional no CAPSIII: Um desafio. Revista Gaúcha de Enfermagem, 26(3), 369-380.

Araújo, F. R. S. Medida de segurança: Caráter Residual da Internação. Recuperado em 30 mar. 2009, em http://jus2.uol.com.br/doutrina/texto.asp?id=10216

Brasil (1984). Lei de Execução Penal. Lei n. 7.210 de 11 de julho de 1984. Institui a Lei de Execução Penal. Diário Oficial [da] República Federativa do Brasil, Poder Legislativo, Brasília, DF, 11 jul. 1984. Recuperado em 17 de junho de 2011, em http:// www.planalto.gov.br/ccivil_03/Leis/L7210.htm 
Brasil. Ministério da Saúde. Secretaria Executiva. Secretaria de Atenção à Saúde. (2004). Legislação em Saúde Mental: 1990-2004. (5a ed). Brasília: Ministério da Saúde.

Brasil. Ministério da Saúde. (2005). Reforma Psiquiátrica e política de saúde mental no Brasil. Documento apresentado a Conferência Regional de Reforma dos Serviços de Saúde Mental: 15 anos depois de Caracas. Brasília: Ministério da Saúde.

Brasil. Ministério da Saúde. Pacientes de saúde mental se recuperam melhor em convívio social. Recuperado em 18 jun. 2009, em http://portal.saude.gov.br/por$\mathrm{tal} /$ saude/visualizar_texto.cfm?idtxt $=24128$.

Castro U. R. (2009). Reforma psiquiátrica e o louco infrator: Novas idéias e novas práticas. Dissertação de Mestrado, Instituto de Ciências Ambientais e da Saúde da Universidade Católica de Goiás, Goiânia.

Correia, L. C., Lima, I. M. S. O., Alves, V. S. (2007). Direitos das pessoas com transtorno mental autoras de delitos. Cadernos de Saúde Pública, 23(9), 1995-2012.

Dantas, M. A., \& Chaves, A. M. (2007). Saúde custodiada: Representação dos Guardas Sobre o Hospital de Custódia. Psicologia Ciência e Profissão, 27(2), 342-357.

Foucault, M. (2007). História da loucura: Na idade clássica. São Paulo: Perspectiva.

Giovani, C. C. P. (2005). Medida de segurança: Prisão perpétua para o delinqüente psicopata. Monografia de conclusão de curso, Fundação Educacional do município de Assis, SP, Assis.

Lisboa, M. E. S. (2002). Uma experiência em atendimento psicológico ambulatorial num CAPS a pacientes portadores de HIV/AIDS. Trabalho apresentado no $3^{\circ}$ Congresso de Comunicação: Ciência Social e Comportamental. Recuperado em 18 jun. 2009, em http://www.aidscongress.net/article. php?id_comunicacao $=94$

Lopes, T. R. (2002). O caráter perpétuo da medida de segurança. Monografia de conclusão de curso, Faculdade de Direito de Curitiba, PR, Curitiba.

Milhomem, M. A. G. C., \& Oliveira, A. G. B. (2007). O trabalho em equipe nos Centros de atenção psicossocial - CAPS. Cogitare Enfermagem, 12(1), 101-108.

Nucci, G. S. (2006). Manual de Direito Penal: Parte geral, parte especial. (2a ed). São Paulo: Revista dos Tribunais.
Nunes, E. P. F., Bueno, J. R., \& Nardi, A. E. (2001). Psiquiatria e saúde mental: Conceitos clínicos e terapêuticos fundamentais. São Paulo: Atheneu.

Oliveira, A. S. (2009). A codificação do direito. Jus Vigilantibus. Recuperado em 27 mar. 2009, em http://jusvi.com/doutrinas_e_pecas/ver/1894

Oliveira, J. J. B. (2006). Código penal comentado. (3a ed). Rio de Janeiro: Freitas Bastos.

Onocko Campos, R. T., \& Furtado, J. P. (2006). Entre a saúde coletiva e a saúde mental: Um instrumental metodológico para a avaliação da rede de centros de atenção psicossocial (CAPS) do SUS. Cadernos de Saúde Pública, 23(10), 2375-2384.

Peduzzi, M. (2001). Equipe multiprofissional de saúde: Conceito e tipologia. Revista de Saúde Pública, 35(1), 103-109.

Peres, M. F. T., \& Nery Filho, A. (2002). A doença mental no Direito Penal brasileiro: Inimputabilidade, irresponsabilidade, periculosidade e medida de segurança. História, Ciências, Saúde-Manguinhos, 9(2), 335-355.

Prado, L. R. (2006). Curso de direito penal brasileiro (Vol. 2). São Paulo: Revista dos Tribunais.

Ramos, F. A. C., \& Geremias, L. Instituto Philippe Pinel: Origens históricas. Secretaria Municipal do Rio de Janeiro. Recuperado em 22 maio 2009, em http:/ / www.sms.rio.rj.gov.br/pinel/media/pinel_origens.pdf

Santos, S. F. M. (2007). CAPS Judiciário: Uma inovação necessária. Monografia de conclusão de curso, Faculdades Integradas do Planalto Central, Brasília.

Valamiel, N. A. N. (1994). O louco infrator e a medida de segurança. Monografia de conclusão de curso, Curso de especialização em psiquiatria forense CIEPF, Barbacena.

Wunderlich, A. Os casos de Piérre Rivière e Febrônio Índio do Brasil como exemplos de uma violência institucionalizada. Recuperado em 17 out. 2006, em http://jus2.uol.com.br/doutrina/texto.asp?id=1013

Recebido: 17/04/2010 Received: 04/17/2010

Aprovado: 04/08/2010

Approved: 08/04/2010 